Article

\title{
Distribution of Pigeon Pea Cyst Nematode and Root-Knot Nematodes in Major Sesame Growing Areas in Myanmar
}

\author{
Yu Yu Min ${ }^{1, *}$, Thu Htet Naing ${ }^{1}$, Nwe Nwe Htun ${ }^{2}$, Aung Kyaw Myint ${ }^{3}$, Yuri Ichinose ${ }^{4}(\mathbb{D}$, \\ Roland N. Perry ${ }^{5}$, Atsushi Yoshimura ${ }^{6}$ and Koki Toyota ${ }^{4, *}$ (i) \\ 1 Department of Agricultural Microbiology, Yezin Agricultural University, Yezin, Zay Yar Thri, \\ Nay Pyi Taw 15013, Myanmar; thuhtetnaing@yau.edu.mm \\ 2 Department of Agriculture, Ministry of Agriculture Livestock and Irrigation, Magway Township Office, \\ Magway Division 04012, Myanmar; akauk.yau@gmail.com \\ 3 Loongyaw Campus, Yezin Agricultural University, Kyaukse 05151, Myanmar; niwincho@gmail.com \\ 4 School of Bio-Applications and Systems Engineering, Tokyo University of Agriculture and Technology, \\ 2-24-16, Nakacho, Koganei, Tokyo 184-8588, Japan; yurijpjp@gmail.com \\ 5 School of Life and Medical Sciences, University of Hertfordshire, Hatfield, Hertfordshire AL10 9AB, UK; \\ r.perry2@herts.ac.uk \\ 6 Faculty of Agriculture, Kyushu University, Fukuoka 819-0395, Japan; ayoshi@agr.kyushu-u.ac.jp \\ * Correspondence: dr.yuyumin@yau.edu.mm (Y.Y.M.); kokit@cc.tuat.ac.jp (K.T.)
}

Received: 14 July 2020; Accepted: 17 September 2020; Published: 23 September 2020

\begin{abstract}
The pigeon pea cyst nematode, Heterodera cajani, is an economically important plant-parasitic nematode in sesame production. The objective of the study was to investigate distribution of H. cajani in the major sesame producing areas in Myanmar. Before cultivation, soil samples were collected in 96 local farmer's fields: (19 fields in Magway, 20 fields in Mandalay, 14 fields in Sagaing and 43 in Nay Pyi Taw), and nematode density was quantified by real-time PCR. The cyst nematode was detected in $63.2 \%$ of the fields in Magway and the mean density was 22.6 eggs equivalent $(20 \mathrm{~g} \mathrm{soil})^{-1}$. In Mandalay and Nay Pyi Taw, the cyst nematode was detected in $40.0 \%$ and $18.6 \%$ of the fields with the mean densities of 9.9 and 21.0 eggs equivalent $(20 \mathrm{~g} \text { soil })^{-1}$, respectively. By contrast, the cyst nematode was not detected in Sagaing fields, in which sesame is rotated with paddy rice. Infestation of root-knot nematodes (RKN, Meloidogyne spp.) was also evaluated, because sesame is generally rotated with rice and pulses, which are attacked by RKN. The results showed $25.6 \%$ infestation of RKN with a mean density of 34.3 eggs equivalent $(20 \mathrm{~g} \text { soil })^{-1}$ only in Nay Pyi Taw, while there was no infestation in Magway, Mandalay, and Sagaing. The relationships between the nematode infestation level and the cropping patterns in each sesame growing area in Myanmar were discussed.
\end{abstract}

Keywords: Heterodera cajani; crop rotation; Meloidogyne spp.; Meloidogyne gramanicola; Meoidogyne javanica

\section{Introduction}

In Myanmar, sesame (Sesamum indicum L.) occupies the largest sown area in oilseed crops (approximately 50\%) and its production was ca. 800,000 metric ton in 2017/18 [1]. Sesame is economically important for local consumption and export. Myanmar is the world's second largest producer of sesame. However, sesame yields in Myanmar are low, averaging $570 \mathrm{~kg} \mathrm{ha}^{-1}$ as opposed to other sesame producing countries, e.g., China $1500 \mathrm{~kg} \mathrm{ha}^{-1}$ [2]. Several constraints, such as unstable climate, labor scarcity and diseases caused by several kinds of pathogens including plant-parasitic nematodes, are considered the main reasons for the low yields. 
The pigeon pea cyst nematode, Heterodera cajani, is an important nematode pest in pigeon pea. It has a wide host range including cowpea and sesame [3,4]. The nematode causes considerable yield losses, ranging from 14 to $24 \%$ in pigeon pea in a glasshouse pot experiment with an initial density of 20 juveniles $\left(20 \mathrm{~cm}^{3} \text { soil }\right)^{-1}$ [5]. This soil-borne pest can survive as cysts in the soil for several years and readily move from one location to another in soil adhering to farm implements or by the infested eroded soil, making it difficult to control. In Myanmar, the occurrence of H. cajani was first reported in sesame fields and the nematode was considered to cause damage to sesame [6]. Therefore, the cyst nematode should be considered to be an important pest in sesame.

The central dry zone (CDZ), which comprises parts of Magway, Sagaing, and Mandalay regions, is the major sesame growing areas in Myanmar ( $80 \%$ of the sown area). The CDZ makes up about $35 \%$ of the country's cultivable land area and contributes to $74 \%$ of the country's total sesame production $[1,7]$. The primary crops grown in CDZ are rice, oilseed crops (mainly sesame, groundnut and sunflowers), and pulses (mainly pigeon pea and chickpea) [8].

In general, annual rainfall in the CDZ ranges from 500 to $1000 \mathrm{~mm}$ concentrated into a 4-6 months monsoonal wet season [9]. Agriculture in this area is characterized by a large diversity of cropping pattern and rotation. Green gram, groundnut, pigeon pea, and cowpea are commonly grown in sequence with sesame and the coarse grains, pearl millet, sorghum and maize in upland systems [1]. Sesame is grown in a double-crop system or intercropped with pigeon pea in the monsoon and post-monsoon season (from May to August) and dry season (from December to February). Overall, sesame is grown either with rice or pulses as rotation in both rainy and winter season in all growing areas.

In the CDZ, low productivity threatens current and future production and sustainability. Recently, Herridge et al. [10] reported that substantial yield losses occur in sesame due to root and collar rots caused by diseases. However, research regarding the distribution of and damage by $H$. cajani in the sesame cultivated areas in Myanmar is limited. Katsuta et al. [11] reported that $H$. cajani was detected in only two out of 50 soils, located in Nay Pyi Taw area of Myanmar. However, our previous study focused mainly on paddy fields located in lowland Myanmar, and did not focus on fields cultivated mainly with sesame. Therefore, this study aimed to investigate the distribution of the cyst nematode in the major sesame growing areas of Myanmar (Magway, Sagaing, Mandalay, and Nay Pyi Taw), and to analyze its presence in relation to crop rotation. In addition, as described above, sesame is rotated with rice or pulses and both crops are damaged by different species of root-knot nematodes (RKN), which are economically important plant-parasitic nematodes (PPN), such as Meloidogyne incognita, M. enterolobii, and M. graminicola [12]. If sesame fields are infested with RKN, this will affect the subsequent crop growth. Thus, another objective of this study was to investigate the distribution of RKN in the sesame fields.

\section{Materials and Methods}

\subsection{Description of the Soil Sampling Sites and the Sesame-Based Cropping}

Soil sampling was done in Magway, Sagaing, and Mandalay of the CDZ, which is the major sesame growing area of Myanmar, from 2016 to 2019 (Figure 1). The CDZ of Myanmar lies astride the Ayeyarwady River, between latitudes $19^{\circ} 20^{\prime}$ to $22^{\circ} 50^{\prime}$ and longitudes $93^{\circ} 40^{\prime}$ to $96^{\circ} 30^{\prime}$. Soil was collected at $20^{\circ} 08^{\prime} \mathrm{N}, 94^{\circ} 55^{\prime} \mathrm{E}$ in Magway, at $21^{\circ} 52^{\prime} \mathrm{N}, 95^{\circ} 58^{\prime} \mathrm{E}$ in Sagaing, and at $21^{\circ} 57^{\prime} \mathrm{N}, 96^{\circ} 5^{\prime} \mathrm{E}$ in Mandalay. In addition, soil was collected from $19^{\circ} 44^{\prime} \mathrm{N}, 96^{\circ} 7^{\prime} \mathrm{E}$ in Nay Pyi Taw including Yezin and Tatkone, which is $150 \mathrm{~km}$ to the south of Mandalay and there is a little more rainfall (average annual rainfall; $1151 \mathrm{~mm}$ ) as compared with the CDZ (500 to $1000 \mathrm{~mm}$ ) [9]. Climate condition of CDZ belongs to hot semi-arid climate in Köppen-Geiger climate classification (Figure 1). Part of Nay Pyi Taw belongs to the CDZ. Soil types of our sampling regions are categorized as alluvial in origin [10]. 


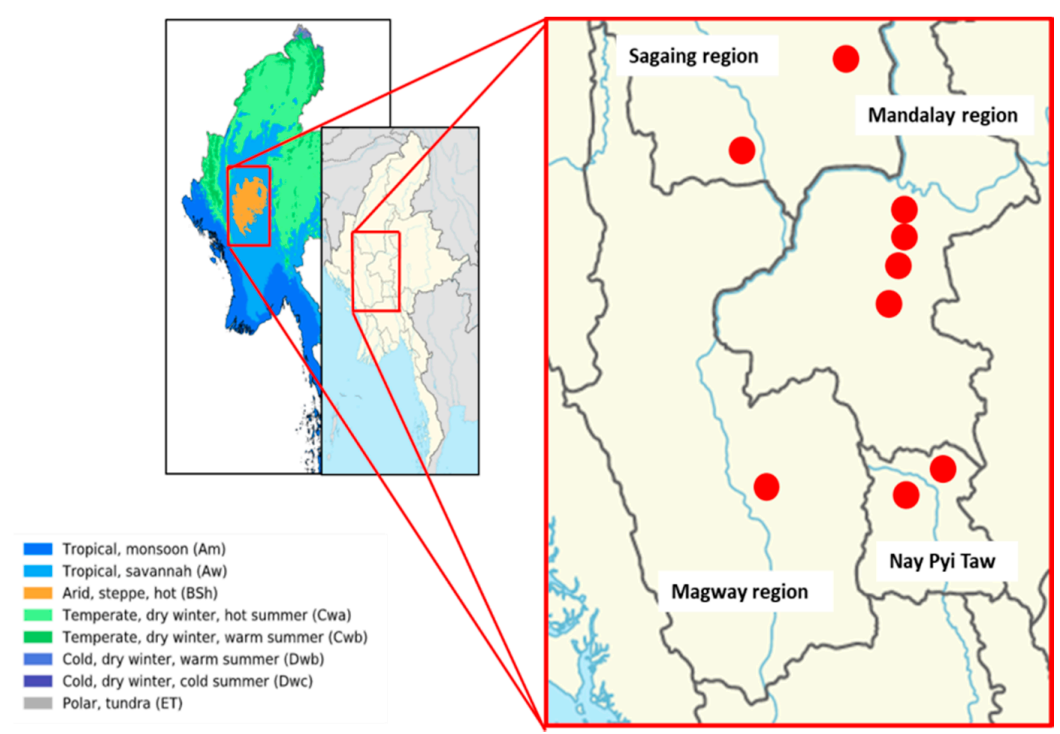

Figure 1. Sampling locations of soils in the four areas of Magway, Mandalay, Sagaing, and Nay Pyi Taw in Myanmar. Left map shows Köppen-Geiger climate classification in Myanmar [13] and the orange area belongs to arid, steppe, and hot climate and corresponds to central dry zone. Center and right maps show the soil sampling locations and red circles in the right map indicate the location of soil sampling.

Typical cropping pattern and timing of cultivation in CDZ are indicated in Figure 2. In monsoon season, sesame, groundnut, green gram, cowpea and pigeon pea are planted in upland, and rice in lowland. In dry season, sesame, chickpea, and groundnut are planted in lowland. Annual crop rotation is determined based on the season and rainfall. In Magway, sesame is cultivated in the upland (rainfed) system and is rotated with pulses all year round. The large proportion of farmers in Magway is engaged in sesame production [14]. Magway produces a large quantity of groundnut and sesame for edible oil. In Mandalay, there are two cropping patterns, i.e., sesame-rice and sesame-pulses. For lowland (irrigated areas), the cropping of sesame (March to June)—Rice (July to November) - Chickpea (December to February) is also practiced. In Sagaing, two kinds of sesame-based cropping are practiced: pulses (March to June) - Rice (June to September)—Sesame (October to December); and sesame (March to June) - Rice or pulses (June to October). Various cropping pattern and rotation are observed in Nay Pyi Taw, where sesame is cultivated from May to July and rotated with rice (August to January) or upland crops only in some cases in which irrigation water is available.

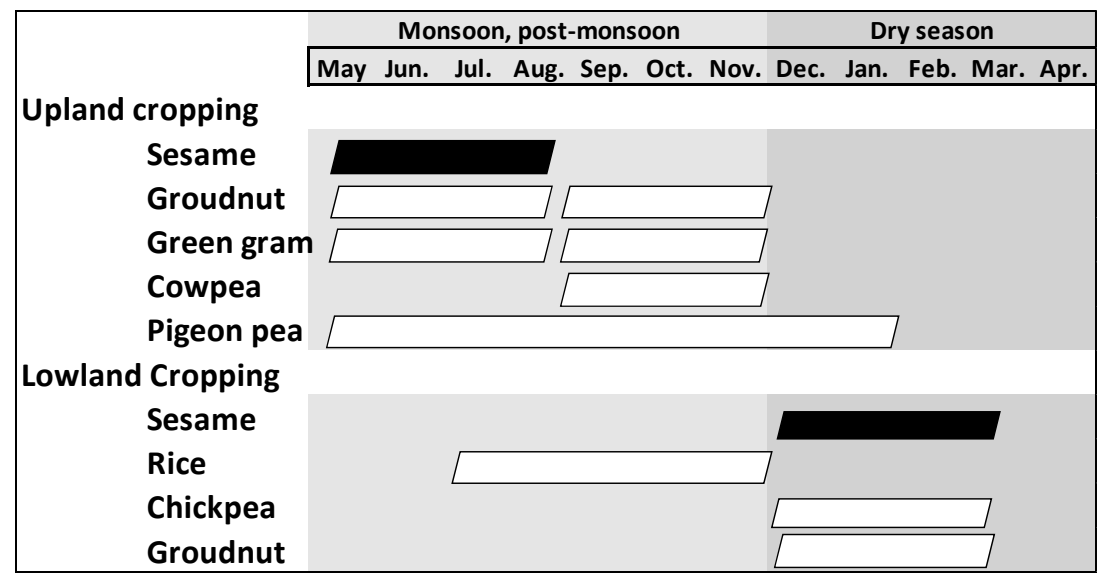

Figure 2. Typical cropping pattern and timing of cultivation of central dry zone in Myanmar. Adapted from [10]. 


\subsection{Soil Sampling}

Soils were sampled from a total of 96 sesame cultivated fields, 19 in Magway, 20 in Mandalay, 14 in Sagaing, and 43 in Nay Pyi Taw area. Soil sampling was done at harvesting time or before cultivation; Magway in August 2016, Nay Pyi Taw in July 2016 and March and October 2017 and Sagaing in March 2019 and in Mandalay in March 2017 and March 2019. We visited sesame cultivated fields in villages through extension workers and directly contacted farmers, and confirmed farmers experiences for growing sesame and types of crops they plan to grow after and before planting sesame. One or two fields were selected randomly in each village to cover a wide area, except for Mandalay in March 2019, in which 12 fields were randomly selected in one village because sesame production was rapidly increasing in the village. Soil samples were taken using a diagonal pattern across the field. A total of five cores (0-15 cm depth) were collected from each field with an auger and made into a composite soil sample (300 g to $600 \mathrm{~g}$ ). Soil samples were put into plastic bags in a cooler box, brought to the laboratory of Yezin Agricultural University, and air-dried for analysis.

The difference of $H$. cajani presence among the four sampling areas were tested by Chi-square test for independence.

\subsection{Nematode Quantification}

Composite soil samples were air-dried at the laboratory and then brought to Japan with soil export permission. In Japan, ca. $200 \mathrm{~g}$ of soil was oven-dried at $60^{\circ} \mathrm{C}$ and $10 \mathrm{~g}$ of the dried soils were taken in duplicate from each sample and pulverized into powder for 2 min at $45 \mathrm{~m} \mathrm{~s}^{-1}$ in a ball-mill (Fast Prep; MP Biomedicals). Soil samples were combined for each sample site $(20 \mathrm{~g})$ and used for DNA extraction. DNA was extracted in duplicate from $0.5 \mathrm{~g}$ of soil using a modified method reported by Min et al. [15]. Soil was mixed with $500 \mu \mathrm{L}$ of skim milk solution $(20 \%$ skim milk, $10 \mathrm{mM}$ Tris- $\mathrm{HCl}$ (pH 8), $50 \mathrm{mM}$ EDTA (ethylenediaminetetraacetic acid) (pH 8), $0.5 \%$ SDS), $5 \mu \mathrm{L}$ of salmon DNA solution $\left(1 \mathrm{mg} \mathrm{mL}^{-1}\right)$ in a 2.0 $\mathrm{mL}$ tube containing $0.75 \mathrm{~g}$ of zirconia beads $(0.1 \mathrm{~mm}$ in diameter $)$ and $0.25 \mathrm{~g}$ of glass beads $(0.5 \mathrm{~mm}$ in diameter) and briefly centrifuged. Then, $600 \mu \mathrm{L}$ of lysis buffer $(0.5 \%$ SDS; $10 \mathrm{mM}$ Tris-HCl, $\mathrm{pH} 8 ; 50 \mathrm{mM}$ EDTA, $\mathrm{pH}$ 8) was added, and the tubes were treated with bead beating ( $5000 \mathrm{rpm}$ for $60 \mathrm{~s}, \times 2$ ) and then centrifuged $\left(12,000 \times g\right.$ for $5 \mathrm{~min}$ at $\left.25^{\circ} \mathrm{C}\right)$. The supernatant was transferred to a new tube containing $377 \mu \mathrm{L}$ of $5 \mathrm{M} \mathrm{NaCl}$ and $270 \mu \mathrm{L}$ of $10 \% \mathrm{CTAB}$ (cetyltrimethylammonium bromide). After $10 \mathrm{~min}$ incubation at $60^{\circ} \mathrm{C}, 500 \mu \mathrm{L}$ of chloroform were added and mixed well. After centrifugation $(15,000 \times g$ for $15 \mathrm{~min}$ at $25^{\circ} \mathrm{C}$ ), the supernatant was transferred to a new tube containing $500 \mu \mathrm{L}$ of chloroform and the tube was mixed well. After centrifugation $\left(15,000 \times g\right.$ for $15 \mathrm{~min}$ at $\left.25^{\circ} \mathrm{C}\right)$, the supernatant was transferred to a new tube and $600 \mu \mathrm{L}$ of $20 \%$ PEG ( $20 \%$ polyethylene glycol, $1.6 \mathrm{M} \mathrm{NaCl})$ was added and the tube was mixed well. After centrifugation $\left(15,000 \times \mathrm{g}\right.$ for $20 \mathrm{~min}$ at $\left.4{ }^{\circ} \mathrm{C}\right)$, all supernatant was discarded and $500 \mu \mathrm{L}$ of $70 \%$ ethanol was added. After centrifugation $\left(15,000 \times g\right.$ for 5 min at $\left.4{ }^{\circ} \mathrm{C}\right)$, all supernatant was discarded, and the tube was dried using a VC-15Sp (Taitec) for $20 \mathrm{~min}$. Finally, 100 $\mu \mathrm{L}$ of TE (Tris-EDTA, $\mathrm{pH}$ 8.0) was added and incubated for $1 \mathrm{~h}$ at room temperature to dissolve the precipitated DNA. The DNA extract was used as template in real-time PCR after ten-fold dilution. Real-time PCR was performed using a Step One Real-Time PCR System (Life Technologies Japan) in a final volume of $10 \mu \mathrm{L}$ containing $5 \mu \mathrm{L}$ of a Fast SYBR Green Master Mix (Life Technologies Japan), 5 $\mathrm{mM}$ of each primer and $2 \mu \mathrm{L}$ of template DNA under the manufacturer's recommended conditions (95 ${ }^{\circ} \mathrm{C}$ for $10 \mathrm{~s}$, $\left(95^{\circ} \mathrm{C}\right.$ for $5 \mathrm{~s}$ and $60^{\circ} \mathrm{C}$ for $\left.20 \mathrm{~s}\right) \times 40$ cycles). The density of $H$. cajani was quantified by using the species-specific primer set (Table S1) and calibration curve $(\mathrm{y}=-1.1132 \mathrm{x}+32.232, \mathrm{y}=\mathrm{Ct}$ value, $x=\log _{2}\left(\right.$ No. of nematodes $\left.\left.(10 \mathrm{~g} \text { soil })^{-1}\right)\right)$ developed by Katsuta et al. [12]. Since the calibration curve was prepared using egg suspensions, the density of $H$. cajani was expressed as eggs equivalent.

The presence/absence of RKN was also checked using Meloidogyne genus primers (Mel) developed in this study (Table 1). Pulses and rice are damaged by different Meloidogyne spp. and thus a genus-specific primer set for Meloidogyne was developed to detect a wide range of Meloidogyne spp. that are commonly found in economically important crops such as rice, pulses and sesame $[16,17]$. This new primer set (Mel-f and Mel-f) designed in the 18S rRNA gene perfectly matched with most 
of the Meloidogyne spp. (Table 1, Figure S1) and showed at least 12 base pair mismatches with the other genera, such as Hirschmanniella, Ditylenchus, Tylenchus, Hoplolaimus, Pratylenchus, Heterodera, and Helicotylenchus. These In-silico analyses indicated no amplification to the nematodes except for Meloidogyne spp. The density (x, Log No. (egg equivalent) (20 g soil) $)^{-1}$ of Meloidogyne spp. in the soil samples was calculated based on the calibration curve of ( $\mathrm{y}, \mathrm{Ct}$ value), which was produced using a Japanese andosol and by inoculating different numbers of eggs of $M$. incognita. To identify the RKN species., the samples that showed positive reactions to the Mel primer set were further tested using the real-time PCR primer set, RKN which is specific to M. incognita, M. arenaria and M. javanica [18], and the primer set specific to the species M. graminicola [11] (Table S1). The RKN primer set amplifies DNA from M. incognita, M. arenaria and M. javanica at the same efficiency and is impossible to discriminate among three species. However, it enables separation from the other Meloidogyne spp. such as M. graminicola, M. enterolobii and M. hapla.

Table 1. Comparison of the sequences in the positions of the Meloidogyne genus primer set developed in this study.

\begin{tabular}{|c|c|c|}
\hline \multirow{2}{*}{$\begin{array}{l}\text { Nematode Species for Sequence } \\
\text { Comparison (Accession No.) }\end{array}$} & \multicolumn{2}{|c|}{ Sequences $\left(5^{\prime}-3^{\prime}\right)$ in the Positions of Specific Primer Set } \\
\hline & Forward (Mel-f) & Reverse (Mel-r) \\
\hline Meloidogyne chitwoodi KP901059 & ATCA-ACTT-GACGGGAGCATAATC & CTCG_AGCCGAGAGTGGGTAA \\
\hline M. enterolobii MN661336 & ATCA-ACTT-GACGGGAGCATAATC & CTCG-AGCCGAGAGTGGGTAA \\
\hline M. ethiopica LN626932 & ATCA-ACTT-GACGGGAGCATAATC & CTCG_-AGCCGAGAGTGGGTAA \\
\hline M. exigua AF442200 & ATCA-ACTT-GACGGGAGCATAATC & CTCG-AGCCGAGAGTGGGTAA \\
\hline M. floridensis AY942621 & ATCA-ACTT-GACGGGAGCATAATC & CTCG_-AGCCGAGAGTGGGTAA \\
\hline M. graminicola MK301102 & ATCA-ACTT-GACGGGAGCATAATC & CTCG-AGCCGAGAGTGGGTAA \\
\hline M. graminis KP901056 & ATCA-ACTT-GACGGGAGCATAATC & CTCG-AGCCGAGAGTGGGTAA \\
\hline M. hapla MH011983 & ATCA-ACTT-GACGGGAGCATAATC & CTCG-AGCCGAGAGTGGGTAA \\
\hline M. incognita MN661338 & ATCA-ACTT-GACGGGAGCATAATC & CTCG-AGCCGAGAGTGGGTAA \\
\hline M. mayaguensis AY942629 & ATCA-ACTT-GACGGGAGCATAATC & CTCG-AGCCGAGAGTGGGTAA \\
\hline M. paranaensis AY942622 & ATCA-ACTT-GACGGGAGCATAATC & CTCG-AGCCGAGAGTGGGTAA \\
\hline M. aberrans MF278756 & ATCA-ACCT-GATGGTAGCATAAAC & CTCG-TGCCGAGAGTGGGTAA \\
\hline M. ichinohei EU669953 & ATCATACTT-GATGTTAGTATCAGT & CTCG-TACCGAGAGTGGGTAA \\
\hline M. duytsi AF442197 & ATCA-ACTT-GACGGGAGCATAACC & CTCG-AGCCGAGAGTGGGTAA \\
\hline M. microtyla AF442198 & ATCA-ACTT-GACGGGAGCATAATT & CTCG-AGCCGAGAGTGGGTAA \\
\hline M. artiellia KC875392 & ATCA-ACTT-GACGGGAGTATAATC & CTCG-TGCCGAGAGTGGGTAA \\
\hline M. mali KJ636400 & ATCA-ACTT-GATGGGAGCATAATT & CTCG-TGCCGAGAGTGGGTAA \\
\hline M. oleae MH011980 & ATCA-ACTT-GACGGGAGCATAACC & CTCG-AACCGAGAGTGGGTAA \\
\hline M. africana KY433422 & ATCA-ACTT-GAAGGGAGCATAATC & CTCT-AGCCGAGAGTGGGTAA \\
\hline M. coffeicola HE667739 & ATCA-ACTT-GAAGGGAGCATAATT & CTCG-TGCCGAGAGTGGGTAA \\
\hline Hirschmanniella oryzae KF366906 & ATCA-ACTTTCGATGGTAGTGTATCT & CTCA-CTCTGAGAGTGGGTAA \\
\hline Ditylenchus destructor AY593912 & ATCA-ACTTTCGATGGTAGTGTATGT & CTCA-TTCTGAGAGTGGGTAA \\
\hline Tylenchus arcuatus EU306349 & ATCA-ACTTTCGATGGTAGTGTATCT & CTCAATGCTCTGAGAGTGGGTAA \\
\hline Hoplolaimus columbus KJ934149 & ATCA-ACTTTCGATGGTAGTATACAG & CTCA-TCTTGAGAGTGGGTAA \\
\hline Pratylenchus neglectus EU130802 & ATCA-ACTTTCGATGGTAGTGTATGT & CTCA-AATCGAGAGTGGGTAA \\
\hline Heterodera glycines AY043247 & ATCA-ACTTTCGATGGTAGTGTATCT & CTCG-CCTTGAGAGTGGGTAA \\
\hline Helicotylenchus dihystera AJ966486 & ATCA-ACTTTCGATGGTAGTGTACCT & CTCG_CCTTGAGAGTGGGTAA \\
\hline
\end{tabular}

\section{Results}

Heterodera cajani was detected in Magway, Mandalay, and Nay Pyi Taw, but not in Sagaing (Table 2). In Magway, H. cajani was detected in $63.2 \%$ of the fields with an average density of 22.6 eggs equivalent $(20 \mathrm{~g} \text { soil })^{-1}$. In Mandalay, H. cajani was detected in $40.0 \%$ of the fields with an average density of 9.9 eggs equivalent $(20 \mathrm{~g} \text { soil })^{-1}$ and $18.6 \%$ of the fields in Nay Pyi Taw with an average density of 21.0 eggs equivalent $(20 \mathrm{~g} \text { soil })^{-1}$.

The frequency of $H$. cajani infested fields varied among four sampling areas. Chi-square test showed that the frequency of occurrence of $H$. cajani in sesame fields was not the same among the four sampling areas at $1 \%$ significant level (Chi-square value $=19.849, \mathrm{df}=3, p<0.01$ ). The significant difference among the four areas was caused by the absence of $H$. cajani in Sagaing and the highest infestation percentage in Magway. 
Table 2. The density of Heterodera cajani in soils of four sesame growing areas in Myanmar.

\begin{tabular}{|c|c|c|c|c|c|c|c|c|c|c|c|c|c|}
\hline Area & & & e $\mathrm{D}$ & nsit & $y * i$ & Each & Field & & & & $\begin{array}{l}\text { No. of Infested } \\
\text { Fields (\%) }\end{array}$ & No. of Fields & $\begin{array}{l}\text { Average Density * } \\
\text { (Range) }\end{array}$ \\
\hline Magway & $\begin{array}{c}100 \\
2\end{array}$ & $\begin{array}{l}0 \\
0\end{array}$ & $\begin{array}{l}7 \\
78\end{array}$ & $\begin{array}{l}0 \\
0\end{array}$ & $\begin{array}{l}61 \\
0\end{array}$ & $\begin{array}{l}13 \\
36\end{array}$ & $\begin{array}{l}15 \\
0\end{array}$ & $\begin{array}{l}0 \\
13\end{array}$ & $\begin{array}{l}12 \\
77\end{array}$ & 15 & $12(63.2)$ & 19 & $22.6(0-100)$ \\
\hline Mandalay & $\begin{array}{l}0 \\
6\end{array}$ & $\begin{array}{l}0 \\
1\end{array}$ & $\begin{array}{l}0 \\
13\end{array}$ & $\begin{array}{l}0 \\
1\end{array}$ & $\begin{array}{l}0 \\
0\end{array}$ & $\begin{array}{c}0 \\
125\end{array}$ & $\begin{array}{l}0 \\
21\end{array}$ & $\begin{array}{l}0 \\
25\end{array}$ & $\begin{array}{l}0 \\
0\end{array}$ & $\begin{array}{l}0 \\
7\end{array}$ & $8(40.0)$ & 20 & $9.9(0-125)$ \\
\hline Sagaing & $\begin{array}{l}0 \\
0\end{array}$ & $\begin{array}{l}0 \\
0\end{array}$ & $\begin{array}{l}0 \\
0\end{array}$ & $\begin{array}{l}0 \\
0\end{array}$ & 0 & 0 & 0 & 0 & 0 & 0 & $0(0.0)$ & 14 & $0.0(0)$ \\
\hline Nay Pyi Taw & $\begin{array}{c}0 \\
1 \\
0 \\
166 \\
0\end{array}$ & $\begin{array}{c}0 \\
0 \\
0 \\
223 \\
0\end{array}$ & $\begin{array}{l}0 \\
0 \\
0 \\
0 \\
0\end{array}$ & $\begin{array}{l}26 \\
0 \\
0 \\
0\end{array}$ & $\begin{array}{l}0 \\
0 \\
47 \\
0\end{array}$ & $\begin{array}{c}0 \\
131 \\
0 \\
0\end{array}$ & $\begin{array}{l}0 \\
0 \\
0 \\
0\end{array}$ & $\begin{array}{l}0 \\
0 \\
0 \\
0\end{array}$ & $\begin{array}{l}7 \\
0 \\
0 \\
0\end{array}$ & $\begin{array}{l}0 \\
0 \\
180 \\
122\end{array}$ & $8(18.6)$ & 43 & $21.0(0-223)$ \\
\hline
\end{tabular}

* The density was expressed as eggs equivalent $20 \mathrm{~g}$ soil $^{-1} \cdot{ }^{* *}$ Light gray means the fields detected.

To estimate Meloidogyne spp. population density in soil, a calibration curve $(y=-0.909 x+34.779$, $\mathrm{R}^{2}=0.9597, p<0.01$ ) was obtained (Figure 3 ). In the calibration curve, the minimum density was 5 eggs equivalent $(20 \mathrm{~g} \text { soil })^{-1}$, indicating that this density was the minimum detection limit.

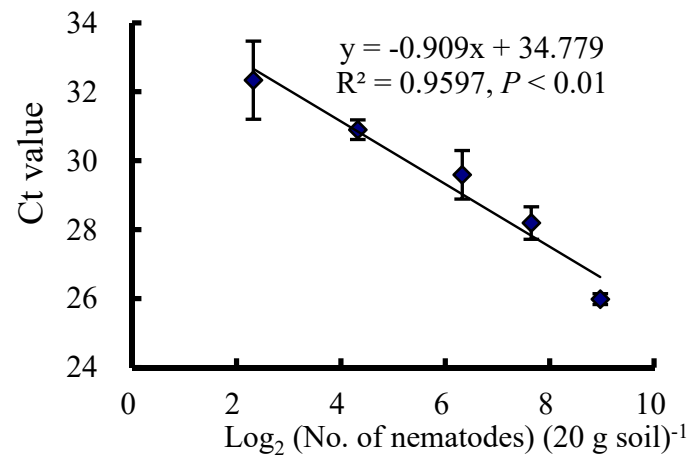

Figure 3. Relationship between the number of Meloidogyne incognita eggs inoculated into $20 \mathrm{~g}$ soil and $\mathrm{Ct}$ values. Values are mean $\pm \mathrm{SD}(n=3)$.

Meloidogyne spp. were not detected in any soil samples from Magway, Mandalay, and Sagaing (Table 3). By contrast, Meloidogyne spp. were detected in $25.6 \%$ of soil samples collected from Nay Pyi Taw (Table 3). Out of 11 infested fields, three fields were also infested with H. cajani. Using the specific primer sets to differentiate Meloidogyne species, M. graminicola was identified in five fields, while four fields were infested only with either of $M$. incognita, M. arenaria or $M$. javanica. Two fields were infested with M. graminicola and M. incognita/M. arenaria/M. javanica.

Table 3. Occurrence of root-knot nematodes (RKN, Meloidogyne spp.) in soils of four sesame growing areas in Myanmar.

\begin{tabular}{cccc}
\hline Area & $\begin{array}{c}\text { No. of Fields Infested with RKN } \\
(\mathbf{\%})\end{array}$ & No. of Fields & $\begin{array}{c}\text { Average Density * of RKN } \\
\text { (Range) }\end{array}$ \\
\hline Magway & $0(0.0)$ & 19 & \\
Mandalay & $0(0.0)$ & 20 & 34.3 \\
Sagaing & $0(0.0)$ & 14 & $(0.8-137.2)$ \\
Nay Pyi Taw & $11(25.6)$ & 43 & \\
\hline
\end{tabular}

* The density was expressed as eggs equivalent $20 \mathrm{~g}$ soil $^{-1}$. 


\section{Discussion}

The quantification method using real-time PCR developed previously and in the present study opened the way to detect and identify PPN effectively, and enables a wide-ranged survey and quantitative evaluation of PPN in soil. This method has also made possible the processing of many soil samples for nematode quantification, which was difficult to conduct before. Applying this method, the distribution of H. cajani and Meloidogyne spp. in sesame cultivated fields in the CDZ of Myanmar was investigated, which had not been investigated well so far.

The occurrence of H. cajani differed depending on the soil sampling locations (Table 2). In CDZ, sesame is mostly cultivated in rotation with either rice or pulses and is intercropped with pulses. Magway, where sesame is intensively cultivated in rotation with pulses but not with paddy rice, showed the highest frequency of $H$. cajani occurrence. On the other hand, no H. cajani was detected in Sagaing, where rice cultivation is practiced predominantly in monsoon and post-monsoon seasons and sesame is cultivated in dry season. These observations lead us to speculate that rice cultivation is not favorable for the occurrence of H. cajani. Indeed, rice is not a host of H. cajani [16] and the density of another cyst nematode, $H$. glycines, decreased to one third and nearly zero after one time and two times cultivation of paddy rice, respectively [19]. Further research is needed focusing on field experiments and observations of cropping history in specific fields.

In upland areas of Magway, sesame is intensively cultivated with a rotation with pulses or intercropped with pigeon pea or groundnut. We noticed that sesame was always rotated with other crops, but was not rotated with paddy rice in any survey areas in Magway. Our sampling fields were rotated with groundnut or green gram, and farmers left fields to fallow depending on the next crops after sesame. These practices might reflect the wide presence of $H$. cajani, because green gram is a susceptible host of $H$. cajani [16] although the relationship between $H$. cajani and groundnut is not known.

In Mandalay, our sampling fields are located at the central Mandalay which was an irrigated lowland area. Farmers in these areas cultivate paddy rice from July to November, chickpea from December to February, and then sesame from March to June. All the eight infested fields were in one particular area of Mandalay. In this area, sesame cultivation started recently instead of rice, because of the high marketable prices of sesame. Detection of high level (40.0\%) of $\mathrm{H}$. cajani in the area might be due to the rotation with chickpea and sesame, which are host plants [20].

In many sampling fields in Nay Pyi Taw, sesame was rotated with rice or pulses depending on the accessibility to water in the year. The observation of higher infestation and densities of H. cajani in Nay Pyi Taw could be related to non-rotation with paddy rice and rotation with black gram or cowpea in the areas, although we failed to identify the exact cropping pattern and rotation in each field.

Meloidogyne spp. were also not detected in the soils of Sagaing, indicating that rotation with paddy rice might be effective to control these PPN, due to the flooded conditions [21]. Indeed, Heterodera and some other PPN were not detected in paddy rice fields [22].

Meloidogyne spp. attack a wide range of plants and can damage economically important crops, such as rice and pulses worldwide $(17,18)$. In this study, we did not detect Meloidogyne spp. in the soil collected in all sesame cultivated areas of Magway, Mandalay, and Sagaing, where rotation with rice or pulses is practiced. Various studies on sesame revealed that sesame root diffusate inhibits the activity of second-stage juveniles of $M$. incognita; among the compounds in diffusate, including aspartic acid, glutamic acid, glycine, leucine, proline, serine valine and free amino acids there are specific movement inhibitors that require further investigation $[23,24]$.

By contrast, in Nay Pyi Taw areas $26 \%$ of the fields were infested with Meloidogyne spp. and on three fields both nematodes, H. cajani and Meloidogyne spp., were detected. In fact, cropping pattern and rotation in Nay Pyi Taw are diversified and changed year by year depending on the water availability and conditions of the field, which makes difficult to determine why these two important nematodes occurred. 
Seven fields were infested with M. graminicola, which attacks rice, green gram, sorghum, soybean, etc. [18], but does not attack sesame, groundnut, cowpea and pigeon pea [17]. These results suggest that $M$. graminicola reproduce in rice or green gram and survive in other crops. Using the RKNf/r primers, it is impossible to differentiate $M$. incognita, $M$. arenaria and $M$. javanica. In this study, $M$. incognita/M. arenaria/M. javanica were identified in six fields. According to the previous microscopic observation (reviewed by [17]), sesame and sunflower were damaged by RKN, more specifically M. javanica. Meloidogyne javanica attacks a wide range of crops, including cowpea, groundnut and pigeon pea [17], which are the major rotation crops in Nay Pyi Taw. Therefore, there might be a possibility that M. javanica can be present in Nay Pyi Taw.

\section{Conclusions}

Myanmar grows diversified crops based on the geographical and climate conditions and its water accessibility. This study was the first survey of distribution of H. cajani and Meloidogyne spp. in CDZ of Myanmar and suggested that $H$. cajani and Meloidogyne spp. might be suppressed by rotation with paddy rice in the sesame cropping. In upland conditions, sesame would suppress RKN if rotated with pulses. Crop rotation would be an important countermeasure to control plant PPN such as pigeon pea cyst nematode and RKN, both economically important pests for sesame and pulses production.

Supplementary Materials: The following are available online at http://www.mdpi.com/2073-4395/10/10/1457/s1, Table S1: Sequences of the real-time PCR primer sets used in this study. Figure S1: Phylogenic tree of Meloidogyne spp. (accession No.) based on the 18S rRNA sequences which are available in the NCBI Taxonomy database.

Author Contributions: Y.Y.M. conceptualized; Y.Y.M., K.T., A.Y., conducted the experiments and collected field data; T.H.N.; assisted soil samplings; A.K.M.; provided local farmers information N.N.H.; Y.I. collected references; Y.Y.M. wrote the paper; A.Y., R.N.P. and K.T. reviewed, edited, and finalized the paper. All authors have read and agreed to the published version of the manuscript.

Funding: This work was funded by JICA (Japan International Cooperation Agency for YAU Technical cooperation project, and Grant-in-Aid for Scientific Research from ministry of Education, Science, Sports and Culture of Japan (No. 16H05782).

Acknowledgments: Y.Y.M. acknowledge local farmers and staff of the Myanmar Department of Agriculture (DoA) for assistance in conducting soil sampling. We also thank Mae, H. and Oda, S. who helped us in soil analyses.

Conflicts of Interest: The authors declare no conflict of interest.

\section{References}

1. MOALI. Myanmar Agriculture at a Glance 2016; Department of Planning, Ministry of Agriculture, Livestock and Irrigation: Nay Pyi Taw, Myanmar, 2018; 166p.

2. FAOSTAT. Food and Agricultural Organization of the United Nations Statistics. 2018. Available online: http://www.fao.org/documents/card/en (accessed on 31 August 2019).

3. Koshy, P.K.; Swarup, G. Susceptibility of plants to pigeon-pea cyst nematode, Heterodera cajani. Ind. J. Nematol. 1972, 2, 1-6.

4. Senthamiz, K.; Rajendran, G.; Subramanian, S. Host range, biology and races of Heterodera cajani Koshy, 1967 occurring in Tamil Nadu (India). Ind. J. Nematol. 2005, 2, 187-191.

5. Sharma, S.B.; Remanandan, P.; Jain, K.C. Resistance to cyst nematode (Heterodera cajani) in pigeonpea cultivars and in wild relatives of Cajanus. Ann. Appl. Biol. 1993, 123, 75-81. [CrossRef]

6. Myint, Y.Y.; Lwin, T.; Thwe, K.H.; Min, Y.Y.; Aye, S.S.; Lin, M.; Kyi, P.P.; Maung, Z.T.Z.; Than, P.P. New record on the occurrence of cyst nematode, Heterodera cajani Koshy, 1967 on sesame, Sesamum indicum, in Myanmar. In Proceedings of the Fourth Agricultural Research Conference in Commemoration of the Ruby Jubilee of Yezin Agricultural University, Nay Pyi Taw, Myanmar, 17-18 February 2005.

7. Hadden, R.L. The Geology of Burma: An Annotated Bibliography of Burma's Geology, Geography and Earth Science; US Army Corps of Engineers: Alexandria, VA, USA, 2008; p. 19. Available online: https://apps.Dtic.mil/dtic/ tr/fulltext/u2/a487552.pdf (accessed on 13 September 2020). 
8. Data Collection on Agriculture Sector in the Republic of the Union of Myanmar. Available online: https://www.themimu.info/sites/themimu.info/files/documents/Assesst_Survey_on_Agriculture_JICA_ Dec2013.pdf (accessed on 13 September 2020).

9. Myanmar-Climate/Britannica. Available online: https://www.britannica.com/place/Myanmar/Climate (accessed on 30 August 2020).

10. Herridge, D.F.; Win, M.M.; New, K.M.M.; Kyu, K.L.; Win, S.S. The cropping systems of the Central Dry Zone of Myanmar: Productivity constraints and possible solutions. Agric. Syst. 2019, 169, 31-40. [CrossRef]

11. Katsuta, A.; Toyota, K.; Min, Y.Y.; Maung, T.T. Development of real-time PCR primers for the quantification of Meloidogyne graminicola, Hirschmanniella oryzae and Heterodera cajani, pests of the major crops in Myanmar. Nematology 2016, 18, 257-263. [CrossRef]

12. Invasive Species Compendium. Available online: https://www.cabi.org/isc/datasheet/40612 (accessed on 30 August 2020).

13. Köppen-Geiger Climate Classification Map for Myanmar. Available online: https://en.m.wikipedia.org/wiki/ File:Koppen-Geiger_Map_MMR_present.svg (accessed on 10 September 2020).

14. Thuzar, L. Value Chain Analysis of Sesame in Magway Township; Research Working Paper Series; Paper NO. 5/2013; Mekong Institute, Newzeland Foreign Affair and Trade Aids Programme: Khon Kaen, Thailand, 2013.

15. Min, Y.Y.; Toyota, K.; Sato, E. A novel nematode diagnostic method using the direct quantification of major plant parasitic in soil by real time PCR. Nematology 2012, 14, 265-276. [CrossRef]

16. Nemaplex. Available online: http://nemaplex.ucdavis.edu/Uppermnus/topmnu.htm (accessed on 30 August 2020).

17. Min, Y.Y.; Toyota, K. Plant-parasitic nematodes in some economically important crops in Myanmar-Species, possible damage and control measures. Nematology 2018, 20,1-13. [CrossRef]

18. Toyota, K.; Shirakashi, T.; Sato, E.; Wada, S.; Min, Y.Y. Development of a real-time PCR method for the potato cyst nematode Globodera rostochiensis and the root-knot nematode Meloidogyne incognita. Soil Sci. Plant Nutr. 2008, 54, 72-76. [CrossRef]

19. Watanabe, M.; Saito, K. Ecological control of Heterodera glycines injurious to azuki bean. Bull. Tochigi Agric. Exp. 1993, 40, 47-58.

20. Castillo, P.; Navas-Cortés, J.A.; Landa, B.B.; Jiménez-Díaz, R.M.; Nicola, V. Plant-parasitic nematodes attacking chickpea and their in planta interactions with rhizobia and phytopathogenic fungi. Plant Dis. 2008, 92, 840-853. [CrossRef] [PubMed]

21. Viaene, C.N.; Coyne, D.L.; Kerry, B.R. Biological and cultural management. In Plant Nematology; Perry, R.N., Moens, M., Eds.; CABI: Wallingford, UK, 2006; pp. 346-369.

22. Namu, J.; Karuri, H.; Alakonya, A.; Nyaga, J.; Njeri, E. Distribution of parasitic nematodes in Kenyan rice fields and their relation to edaphic factors, rainfall and temperature. Trop. Plant Pathol. 2018, 43, 128-137. [CrossRef]

23. Tanda, A.S.; Atwal, A.S.; Bajaj, Y.P.S. In Vitro inhibition of root-knot nematode Meloidogyne incognita by sesame root exudate and its amino acids. Nematologica 1989, 35, 115-124. [CrossRef]

24. Walker, J.T.; Melin, J.B.; Davis, J. Response of Sesamum indicum and S. radiatum. Accessions to root-knot nematode, Meloidogyne incognita. J. Nematol. 1998, 30, 611-615. [PubMed]

(C) 2020 by the authors. Licensee MDPI, Basel, Switzerland. This article is an open access article distributed under the terms and conditions of the Creative Commons Attribution (CC BY) license (http://creativecommons.org/licenses/by/4.0/). 